\title{
Reverse triiodothyronine, thyroid hormone, and thyrotrophin concentrations in placental cord blood
}

\author{
P. G. H. BYFIELD, DAPHNE BIRD, R. YEPEZ, MARIANNE LAND, AND \\ R. L. HIMSWORTH
}

From the Divisions of Clinical Chemistry and Clinical Investigation, Clinical Research Centre and Northwick Park Hospital, Harrow, Middlesex

SUMMARY Reverse triiodothyronine (rT3), triiodothyronine (T3), thyroxine (T4), thyroxine binding globulin (TBG), and thyrotrophin (TSH) were measured in sera from placental cord blood in an unselected series of 272 deliveries. In this series the concentrations of rT3 (mean $3.33 \mathrm{nmol} / 1$, $95 \%$ confidence limits $1 \cdot 6-7 \cdot 0 \mathrm{nmol} / \mathrm{l})$, were log normally distributed and did not overlap the adult normal range $(0 \cdot 11-0 \cdot 44 \mathrm{nmol} / \mathrm{l})$. There were no correlations between the cord blood concentrations of rT3, T3, T4, and TSH. The cord serum rT3 concentration was not influenced by maturity, birthweight, or neonatal risk factors, whereas these factors did affect the concentrations of T3, T4, and TBG. There is no arteriovenous rT3 concentration difference across the placenta, therefore the cord rT3 reflects the systemic rT3 concentration in the baby at birth. As rT3 in the neonate largely, if not entirely, derives from thyroxine from the fetal thyroid, measurement of the cord rT3 concentration may be a good immediate screening test for neonatal hypothyroidism.

Congenital hypothyroidism is a fairly common disorder, often lacking immediate clinical manifestations, in which delayed diagnosis may result in permanent neurological damage owing to a deficiency of thyroid hormones (TH) in the postnatal period. Until the development of radioimmunoassays for TH and thyrotrophin (TSH), attempts to screen all babies for this condition were impracticable. The problem has not been resolved by the introduction of such assays, for at birth the concentrations of the various thyroid-associated hormones differ markedly from the normal levels in children and adults; moreover, in the hours and days after birth they fluctuate widely (Erenberg et al., 1974; Fisher and Sack, 1975). Recently it has been found that reverse triiodothyronine $\left(3,3^{\prime}, 5^{\prime}\right.$ - triiodothyronine, rT3), a metabolically inactive derivative of thyroxine (T4), is present in cord blood at a much higher concentration than in the adult (Chopra et al., 1975). It has been suggested, by a committee of the American Thyroid Association (1976) among others that the cord blood concentration of $\mathrm{rT} 3 \mathrm{might}$ possibly be an indicator of present and future thyroid function in the human newborn infant.

We have recently developed a sensitive radioimmunoassay for rT3 in unextracted serum. In this

Received 13 December 1977 study we examine the interrelations of the serum concentrations of $\mathrm{rT} 3, \mathrm{~T} 4$, triiodothyronine $\left(3,5,3^{\prime}\right.$ triiodothyronine, T3), thyroxine binding globulin (TBG), and TSH in a large number of cord blood samples collected in the obstetric unit of a district general hospital.

\section{Subjects and methods}

Placental cord blood samples were obtained from 272 out of 384 consecutive deliveries in the maternity unit of Northwick Park Hospital. The records of all 384 cases showed that no selection factors were apparent and that the samples were representative of the series as a whole.

Blood was collected from the placental vein by venepuncture after the cord had been clamped and the placenta delivered. The blood having been allowed to clot, the serum was separated and stored at $-20^{\circ} \mathrm{C}$ until assayed.

Reverse T3 was measured by radioimmunoassay using a rabbit rT3 antiserum (final dilution 1:5000) which did not react significantly with other TH or their derivatives (rT3 $100 \%, \mathrm{~T} 40.08 \%, \mathrm{~T} 30.003 \%$ ). ${ }^{125} \mathrm{I}-\mathrm{L}-\mathrm{rT} 3$ was used as a tracer and L-rT3 as standard in the assay. The separation of free from bound antigen was achieved by the addition of a second antibody and centrifugation. In the assay of cord 
samples $200 \mu l$ of a $1: 16$ dilution of serum in buffer was added to the assay tubes which also contained $100 \mu \mathrm{g}$ 8-anilino-naphthalene sulphonic acid to dissociate rT3 from binding proteins.

Thyrotrophin was measured by radioimmunoassay using a rabbit TSH antiserum (MRC 72/356) and ${ }^{125} \mathrm{I}$-hTSH (DE-32-3). The standard in the assay was the WHO 1st International Reference Preparation of Human TSH for immunoassay (68/38). Thyroxine and T3 were also measured by radioimmunoassays which are routinely used in the hospital.

Thyroxine binding globulin was measured by radioautography of 'rocket' immunoelectrophoresis plates of serum samples which had been preincubated with ${ }^{125}$ I-T4 (Drysdale et al., 1975). A pooled serum standard (TDP) was included in each assay and the results were expressed as a percentage of this standard. Because this TDP standard contained a low level of TBG $(6.9 \mathrm{mg} / \mathrm{l})$ the mean normal adult serum concentration by this method is $154 \%$ while in pregnant women the values are approximately $30 \%$ higher.

All measurements were made in duplicate. In a few instances there was insufficient serum to assay each substance, hence the numbers in the subtotals of the tables may differ. The complete data were stored and processed by computer. Results are expressed as means and $95 \%$ confidence limits. In some cases the observed values were log normally distributed (confirmed by plotting the data on probability paper and calculating the difference between the observed and expected distribution) in which case the calculations were made on the log transformed data. It has been assumed that if a group of data is $\log$ normally distributed then subgroups of those data will also be so distributed, and calculations, including the significance of any differences (by $t$ test), have been made accordingly. The probabilities should be regarded with some caution in view of the fact that some tests have been made which are not truly independent of each other.

\section{Results}

Group rT3, T3, T4, TBG, and TSH concentrations. The overall results are set out in Table 1 which also gives the normal ranges for adults measured in the same laboratory as a comparison. The distribution of results for both rT3 and T3 was log normal, as can be seen from Figs. 1 and 2 in which the calculated expected distribution curves are superimposed on the histograms of the actual results. The distribution of all TSH determinations was more nearly log normal than normal but even the transformed data did not conform to any simple pattern (log normal $\left.\chi^{2} 20 \cdot 56,9 \mathrm{df}, 0 \cdot 025>P>0 \cdot 01\right)$. For simplicity the TSH data have been considered to be log normally distributed for the purpose of further analysis. The results for both T4 and TBG did not differ from a normal distribution pattern $(P>0.6$ and $>0.4$ respectively).

Table 1 Placental cord serum concentrations of thyroid hormones, TBG, and TSH compared with the normal range in adults

\begin{tabular}{lllcl}
\hline & \multicolumn{2}{l}{ Cord blood } & $\begin{array}{l}\text { Adults } \\
\text { (normal } \\
\text { range) }\end{array}$ \\
\cline { 2 - 5 } & No. & Mean & $\begin{array}{c}95 \% \text { confi- } \\
\text { dence limits }\end{array}$ \\
\hline rT3 (nmol/1) & 269 & $3 \cdot 33^{*}$ & $1 \cdot 6-7 \cdot 0$ & $0 \cdot 11-0 \cdot 44$ \\
T3 (nmol/1) & 258 & $0 \cdot 59 *$ & $0 \cdot 3-1 \cdot 3$ & $1 \cdot 2-2 \cdot 8$ \\
T4 (nmol/1) & 237 & 126 & $72-180$ & $60-150$ \\
$\begin{array}{l}\text { TBG \% laboratory } \\
\text { standard }\end{array}$ & 268 & 195 & $145-245$ & $122-186$ \\
TSH (mIU/1) & 269 & $11 \cdot 1^{*}$ & $2-62$ & $<5$ \\
\hline
\end{tabular}

*Geometric mean of concentration

Conversion: SI to traditional units-T3: $1 \mathrm{nmol} / 1 \approx 0.65 \mathrm{ng} / \mathrm{ml}$. T4: $1 \mathrm{nmol} / 1 \approx 0.078 \mu \mathrm{g} / 100 \mathrm{ml}$.

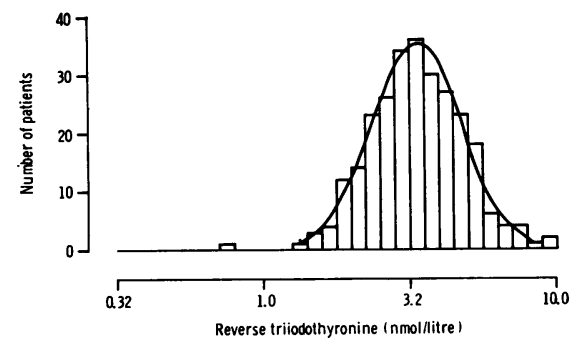

Fig. 1 Serum rT3 concentration in 269 cord blood samples. The values are log normally distributed and the expected distribution curve calculated from the data has been superimposed $\left(\chi^{2} 5 \cdot 28,10 d f, 0 \cdot 90>P>0.8(\prime)\right.$.

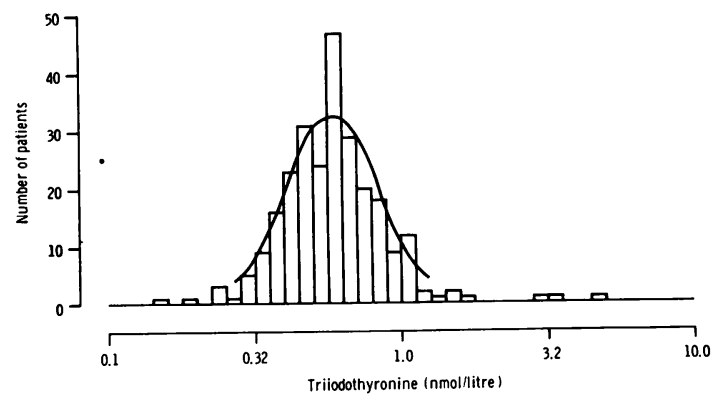

Fig. 2 Serum T3 concentration in 258 cord blood samples. The values are log normally distributed and the expected distribution curve calculated from the data has been superimposed $\left(\chi^{2} 11 \cdot 29,9 d f, 0 \cdot 30>P>0 \cdot 20\right)$. 
It can be seen from Table 1 and Fig. 1 that the mean cord serum rT3 concentration is considerably higher than in adults and that the two ranges do not overlap. In 6 pairs of samples obtained during caesarean sections the cord arteriovenous rT3 concentration difference was measured and found to be negligible. The cord blood results therefore accurately indicate the systemic serum rT3 concentration in the baby at birth. The mean cord serum T3 was less than is usual in adult hypothyroidism. The TBG concentration was elevated and similar to that seen in maternal sera in late pregnancy, while the T4 concentration although raised was not as high as would have been expected in adults with comparable TBG levels. The TSH varied widely and there were 10 results greater than $50 \mathrm{mU} / 1$.

None of the babies from whom samples were obtained has developed hypothyroidism (follow-up $>$ than six months).

Effects of maturity and weight at birth. There were no significant differences in rT3 or TSH in the different categories (Table 2). Serum T4 increased with both maturity and birthweight, these changes being only partly accounted for by the higher TBG levels at term. The $\mathrm{T} 3$ concentration increased with the T4.

Effects of neonatal and maternal risk factors. An attempt was made to assess the effects upon cord TH, TBG, and TSH concentrations of either a difficult delivery or poor state of the baby at birth. Any form of assisted delivery, other than induction

Table 2 Effect of maturity and birthweight upon cord serum thyroid hormone, TBG, and TSH concentrations

\begin{tabular}{|c|c|c|c|c|c|c|}
\hline $\begin{array}{l}\text { Maturity } \\
\text { (weeks) }\end{array}$ & $\begin{array}{l}\text { Birth- } \\
\text { weight } \\
(\mathrm{kg})\end{array}$ & $\begin{array}{l}r T 3 \\
(n m o l / l)\end{array}$ & $\begin{array}{l}\text { T3 } \\
(\mathrm{nmol} / \mathrm{l})\end{array}$ & $\begin{array}{l}\text { T4 } \\
(\mathrm{nmol} / \mathrm{l})\end{array}$ & $\begin{array}{l}\text { TBG \% } \\
\text { laboratory } \\
\text { standard }\end{array}$ & $\begin{array}{l}T S H \\
(m I U / l)\end{array}$ \\
\hline$<38$ & $\leqslant 2.75$ & $\begin{array}{l}3 \cdot 53 \\
1 \cdot 4-8 \cdot 9 \\
(12)\end{array}$ & $\begin{array}{l}0.40^{a} \\
0 \cdot 2-0 \cdot 9 \\
(10)\end{array}$ & $\begin{array}{l}97 d \\
41-153 \\
(10)\end{array}$ & $\begin{array}{l}183 \\
129-237 \\
(12)\end{array}$ & $\begin{array}{l}10 \cdot 5 \\
2-48 \\
(12)\end{array}$ \\
\hline$<38$ & $>2 \cdot 75$ & $\begin{array}{l}2 \cdot 86 \\
1 \cdot 3-6 \cdot 2 \\
(12)\end{array}$ & $\begin{array}{l}0 \cdot 49 b \\
0 \cdot 2-1 \cdot 0 \\
(13)\end{array}$ & $\begin{array}{l}115 \\
77-153 \\
(12)\end{array}$ & $\begin{array}{l}180 g \\
126-234 \\
(12)\end{array}$ & $\begin{array}{l}13 \cdot 5 \\
5-38 \\
(13)\end{array}$ \\
\hline$\geqslant 38$ & $\leqslant 2.75$ & $\begin{array}{l}3 \cdot 05 \\
1 \cdot 3-7 \cdot 0 \\
(19)\end{array}$ & $\begin{array}{l}0 \cdot 53 \\
0 \cdot 2-1 \cdot 2 \\
(18)\end{array}$ & $\begin{array}{l}115 e \\
71-159 \\
(15)\end{array}$ & $\begin{array}{l}195 \\
149-241 \\
(19)\end{array}$ & $\begin{array}{l}10 \cdot 8 \\
1-80 \\
(18)\end{array}$ \\
\hline \multirow[t]{2}{*}{$\geqslant 38$} & $>2.75$ & $\begin{array}{l}3 \cdot 37 \\
1 \cdot 6-6 \cdot 9 \\
(218)\end{array}$ & $\begin{array}{l}0 \cdot 61 c \\
0 \cdot 3-1 \cdot 4 \\
(209)\end{array}$ & $\begin{array}{l}129 f \\
77-181 \\
(193)\end{array}$ & $\begin{array}{l}196 h \\
146-246 \\
(218)\end{array}$ & $\begin{array}{l}11 \cdot 1 \\
2-61 \\
(219)\end{array}$ \\
\hline & $\mathbf{P}$ & & $\begin{array}{l}a-b \\
<0.001 \\
b-c \\
<0.02\end{array}$ & $\begin{array}{l}\text { d-f } \\
<0.001 \\
\text { e-f } \\
<0.05\end{array}$ & $\begin{array}{l}g-h \\
<0.05\end{array}$ & \\
\hline
\end{tabular}

Means and $95 \%$ confidence limits, numbers of samples in parentheses. Significances of the differences between the means of the entire data have been calculated, but only where the probability $(P)$ is $<5 \%$ is the result presented. or episiotomy, was considered to be a maternal 'risk factor'. Because epidural anaesthesia is often used in the maternity unit a relatively large proportion of deliveries were by forceps. Any baby sent to the special care baby unit was taken to be at risk and this included all babies weighing less than $2.5 \mathrm{~kg}$. As before neither the rT3 nor the TSH concentration was affected by these various factors. Maternal risk factors in isolation were without effect on any of the measurements. The TBG, T4, and T3 were all lower in the presence of neonatal risk factors and this was only partially explicable by low birthweight or early delivery.

Correlations. The entire data were examined to see whether there were any simple correlations between the total or free serum concentrations of any of the substances which had been measured. There was none which was especially close. In particular rT3 concentration was unrelated to the levels of the other TH or to TSH. The closest correlation was between $\mathrm{T} 4$ and $\log \mathrm{T} 3$ concentrations $(r=0.45)$. There was a diminishing degree of correlation between the concentration of TBG and those of T4, T3, and $\mathrm{rT} 3(\mathrm{r}=0.28,0 \cdot 10$, and 0.02 respectively). There was no obvious relationship between the $\mathrm{T} 3 / \mathrm{rT} 3$ ratio and $\mathrm{T} 4$ concentration.

\section{Discussion}

Congenital hypothyroidism occurs in approximately 1 in 6000 live births in North America but the prevalence may vary from country to country. Although the role of the thyroid gland in the development of the human fetus is not established, there is no doubt of the need for thyroid hormones in the first months of life. Even among cases of congenital hypothyroidism treated before 6 weeks of age the proportion of children who later have an IQ lower than 90 is greater than expected (MacFaul and Grant, 1977). Ideally therefore any screening programme for the detection of this condition should be based on a sample obtained at birth, or very shortly after, so that it can be processed rapidly to give a reliable indication of the function of the thyroid gland.

At the time of birth, and in the days immediately afterwards, the normal physiological relationships between the various TH and TSH are not yet established. Thus our findings bear out those of many others that, in contrast to the adult situation, the placental cord serum TSH concentration may be markedly elevated in the presence of a normal T4 level, and that there is no simple relationship between the two measurements in any individual case. Furthermore, we have found that there is no 
evident dependence of the serum TSH on the concentration of $\mathrm{T} 3$ in the serum although the latter may be low and comparable to that found in adult hypothyroidism.

Although T4 can be measured in cord blood by methods which are in widespread use, its concentration is determined in part by the size and maturity of the baby (Table 2) and largely by the amount of TBG in the sample. TBG deficiency is not uncommon and the serum concentration of TBG is also reduced in preterm or small babies (Table 2). Thus a low cord blood T4 may not of itself indicate hypothyroidism. Moreover, although the placental cord serum T4 concentration is usually low in babies subsequently shown to have congenital hypothyroidism, values in the lowest part of the normal range have been reported in this condition (Walfish, 1975; Klein et al., 1976).

It seems therefore that none of the measurements used to define hypothyroidism in children and adults can be relied on at the time of birth. As about $10 \%$ of cases of congenital hypothyroidism may result from a failure of TSH secretion (Dussault et al., 1976) any strategy for the detection of hypothyroidism in the newborn infant should be based on the measurement of a product of the thyroid gland; hence the interest in rT3.

Reverse T3 is present in the blood at birth in a concentration greatly in excess of $T 3$, which is the opposite of the situation in adults (Table 1). In our series the mean serum $\mathrm{rT} 3$ concentration was 8 times the upper limit of the normal adult range and the sample with the lowest concentration was twice this upper limit (Fig. 1). These values are similar, allowing for minor assay differences, to those in the smaller series reported by others (Chopra et al., 1975; Burger et al., 1976; Burman et al., 1976; Ratcliffe et al., 1976; Hüfner et al., 1977). The cord serum rT3 concentration at birth largely reflects the output and functioning of the fetal thyroid gland because it is most probably the principal derivative of T4 in the human fetus, and because T4 does not pass in significant amounts directly from the maternal to the fetal circulation (Fisher et al., 1964), although a small amount may reach the fetus through the amniotic fluid. We have found that there is no transplacental rT3 concentration gradient, therefore the concentration of $\mathrm{rT} 3$ in blood obtained from the placental cord after the cord has been cut is the same as that in the baby at birth. Although rT3 derives from $\mathrm{T} 4$ there were no obvious interrelationships between the rT3 concentration in the samples and the concentrations of T4, T3, TBG, and TSH. It seems therefore that rT3 may fulfil the requirements for a suitable substance to measure in a screening programme for congenital hypothy- roidism: it is easily measured by a rapid immunoassay; it is present at birth in a high concentration which is uninfluenced by the weight, maturity, mode of delivery, or condition of the baby; the normal range, conforming closely to a logarithmic distribution is restricted and can be precisely defined. Furthermore, we have found in preliminary studies that $\mathrm{rT} 3$ may be readily eluted from dried spots of blood on filter paper; therefore the handling and processing of many samples should be easy.

There are as yet no reports of the serum rT3 concentration in the cord blood of babies later found to be hypothyroid. In adult hypothyroidism the serum rT3 concentration is relatively more reduced than is the T3 concentration (Ratcliffe et al., 1976), thus the monodeiodination process seems not to be random but to be related to the availability of the substrate, thyroxine. In one serum sample obtained a week after birth from a baby subsequently shown to have hypothyroidism the concentration of rT3 was immeasurable (Burger et al., 1976). It appears probable therefore that the rT3 concentration in congenital hypothyroidism will be subnormal at birth. We feel that the measurement of cord serum rT3 should be further evaluated before deciding on the strategy for a screening programme for congenital hypothyroidism.

We thank Dr F. E. Hytten of the Division of Perinatal Medicine, and the staff of the labour ward for providing samples of cord blood. TSH for iodination was a gift from $\mathrm{Dr} \mathrm{A}$. S. Hartree. The TSH standard was provided by the WHO Laboratory for Biological Standards, London NW3 6RB. Dr D. B. Ramsden assayed the TBG content of our TDP standard. R.Y. held a travelling fellowship from the University of Carabobo, Valencia, Venezuela. Mrs Patricia Davidson gave invaluable secretarial help.

\section{References}

American Thyroid Association (1976). Recommendations for screening programs for congenital hypothyroidism. Journal of Pediatrics, 89, 692-694.

Burger, A., Buerer, T., Sizonenko, P., and Lacourt, G. (1976). Reverse T3 in screening for neonatal hypothyroidism. Lancet, 2, 39-40.

Burman, K. D., Read, J., Dimond, R. C., Strum, D., Wright, F. D., Patow, W., Earll, J. M., and Wartofsky, L. (1976). Measurements of 3,3',5'-triiodothyronine (reverse T3), 3,3'-L-diiodothyronine, T3 and T4 in human amniotic fluid and in cord and maternal serum. Journal of Clinical Endocrinology and Metabolism, 43, 1351-1359.

Chopra, I. J., Sack, J., and Fisher, D. A. (1975). Circulating $3,3^{\prime}, 5^{\prime}$-triiodothyronine (reverse T3) in the human newborn. Journal of Clinical Investigation, 55, 1137-1141. 
Drysdale, I. P., Ramsden, D. B., and Hoffenberg, R. (1975). A routine method for the estimation of thyroxine binding globulin in serum. In Thyroid Hormone Metabolism, pp. 261-279. Edited by W. A. Harland and J. S. Orr. Academic Press: London.

Dussault, J. H., Parlow, A., Letarte, J., Guyda, H., and Laberge, C. (1976). TSH measurements from blood spots on filter paper: a confirmatory screening test for neonatal hypothyroidism. Journal of Pediatrics, 89, 550-552.

Erenberg, A., Phelps, D. L., Lam, R., and Fisher, D. A. (1974). Total and free thyroid hormone concentrations in the neonatal period. Pediatrics, 53, 211-216.

Fisher, D. A., and Sack, J. (1975). Thyroid function in the neonate and possible approaches to newborn screening for hypothyroidism. In Perinatal Thyroid Physiology and Disease, p. 197. Edited by D. A. Fisher and G. N. Burrow. Raven Press: New York.

Fisher, D. A., Lehman, H., and Lackey, C. (1964). Placental transport of thyroxine. Journal of Clinical Endocrinology and Metabolism, 24, 393-400.

Hüfner, M., Grussendorf, M., Lorenz, U., and Knöpfle, M. (1977). 3.3',5'-triiodothyronine (reverse T3) in amniotic fluid and cord serum. European Journal of Pediatrics, 125, 213-217.
Klein, A. H., Foley, T. P., Jr, Larsen, P. R., Agustin, A. V., and Hopwood, N. J. (1976). Neonatal thyroid function in congenital hypothyroidism. Journal of Pediatrics, 89, 545-549.

MacFaul, R., and Grant, D. B. (1977). Early detection of congenital hypothyroidism. Archives of Disease in Childhood, 52, 87-89.

Ratcliffe, W. A., Marshall, J., and Ratcliffe, J. G. (1976). The radioimmunoassay of $3,3^{\prime}, 5^{\prime}$-triiodothyronine (reverse T3) in unextracted human serum. Clinical Endocrinology, 5, 631-641.

Walfish, P. G. (1975). Screening for neonatal hypothyroidism using cord serum T4 measurements: comparisons to neonatal capillary dried blood and serum T4 screening methods. In Perinatal Thyroid Physiology and Disease, p. 249. Edited by D. A. Fisher and G. N. Burrow. Raven Press: New York.

Correspondence to Dr R. L. Himsworth, Clinical Research Centre, Harrow, Middlesex HA1 3UJ. 